\title{
CONSIDERAÇÕES JURÍDICAS E PSICOLÓGICAS ACERCA DO CYBERBULLYING: RESPEITO A DIGNIDADE HUMANA
}

\author{
LEGAL AND PSYCHOLOGICAL CONSIDERATIONS ABOUT \\ CYBERBULLYING: RESPECT FOR HUMAN DIGNITY
}

Marco Antonio Marques da Silva

Professor Titular da Faculdade de Direito da PUC-SP. Conselheiro do Conselho Nacional de Educação-Câmara de Educação Superior. Professor Visitante da Faculdade de Direito da Universidade de Lisboa. Desembargador do Tribunal de Justiça do Estado de São Paulo.

E-mail: mmdsilva@tjsp.jus.br

\section{Evani Zambon Marques da Silva}

Mestre e Doutora em Psicologia pela Pontifícia Universidade Católica de São Paulo PUC-SP. Professora de Psicologia Jurídica da PUC-SP (graduação e lato sensu). Especialista em Psicologia Jurídica (CFP) e no Método de Rorschach. E-mail: ezms@uol.com.br

Recebido em: 27/06/2019 Aprovado em: 13/12/2019

RESUMO: A revolução na comunicação trazida pelos dispositivos eletrônicos é inegável. Se as contribuições não param de crescer, também segue na mesma velocidade o surgimento de problemas e riscos advindos dos novos formatos de comunicação e convivência intermediados pelas máquinas. Dilemas e conflitos permanecem, já que são inerentes à condição humana e adquirem novas dimensões; formas de assédio se perpetuam, sofisticam e ampliam o raio de ação com grande velocidade, atrás do manto de uma suposta obscuridade que o meio eletrônico confere. O direito acaba por ser instado a regular as relações e a coibir práticas danosas que atentem contra os direitos individuais e a convivência em sociedade.

Palavras-chave: Cyberbullying. Dignidade Humana. Assédio Virtual. Crimes Cibernéticos. Direitos Fundamentais.

ABSTRACT: The revolution in communication brought about by electronic devices is undeniable. If the contributions continue to grow, the problems and risks arising from the new forms of communication and coexistence mediated by the machines follow at the same speed. Dilemmas and conflicts remain, since they are inherent to the human condition and acquire new dimensions; forms of harassment perpetuate themselves, sophisticate and magnify the range of action with great speed, behind the mantle of a supposed obscurity that the electronic medium confers. The law ends up being urged to regulate relations and curb harmful practices that violate individual rights and coexistence in society.

Keywords: Cyberbullying. Human Dignity. Virtual Harassment. Cyber Crimes. Fundamental Rights. 
SUMÁRIO: Introdução; 1. Considerações Jurídicas; 1.1 Dignidade Humana; 1.2 Intimidade, vida privada, honra e imagem; 2. Considerações Psicológicas; Conclusão; Referências.

\section{INTRODUÇÃO}

A internet alterou profunda e definitivamente a vida das pessoas sendo inegável o avanço trazido, principalmente quanto a velocidade e quantidade dos dados de comunicação e informação. O caminho é sem volta. O progresso não pode ser contido, embora descobre-se a cada dia vicissitudes diversas embutidas nesse avanço.

A rede mundial de computadores está em constante expansão e vem desde os anos 90 se popularizando principalmente com a oferta e as facilidades da chamada banda larga para uso domiciliar, que democratizou e facilitou a utilização por amplas camadas da população, antes desprovidas ou com remoto acesso ao conhecimento e informação qualificada.

Nos dias de hoje, o mundo virtual faz parte da vida dos seres humanos desde que ele nasce, balbucia as primeiras palavras e inicia seu contato com o mundo físico, são os chamados nativos digitais. Qualquer instituição de ensino utiliza meios eletrônicos diversos para a transmissão do conhecimento; as famílias valem-se cada vez mais cedo de smartphones e tablets para, dentre outras coisas, ensinar, acompanhar, controlar e entreter os filhos. Países como a Ucrânia, a Índia e as Filipinas, por exemplo, tem suas vidas permeadas por redes socais como o Facebook, inclusive para trocas simples de mensagens. É possível dizer, que a sociedade como um todo está em rede e dela já não tem grande possibilidade ou vontade de se libertar.

As pessoas começaram a sentir os efeitos inusitados, e muitas vezes danosos, de situações que fugiam à comunicação usual entre duas pessoas, para uma comunicação onde o emissor e o receptor não são individualizados, mas se referem a uma organização, ou a várias pessoas, cada vez mais à distância, principalmente por meio eletrônico e/ou cibernético. Consequentemente, os conflitos valorativos deixaram de ter um círculo limitado e levaram a dogmática jurídica a depararse com questões sociais e psicológicos, até então desconhecidos.

A velocidade para se transitar entre relações de afeto e de amizades diversas também se alterou; se é fácil multiplicarmos e disseminarmos as alegrias e o amor, também o ódio, as mentiras, as falsas notícias, as palavras de baixo calão ou interpretadas de forma diversa, podem dificultar o perdão, a superação e principalmente o esquecimento.

Porém, é necessário reconhecermos que a era digital é uma realidade em crescimento e que não se pode dela alijar os cidadãos; é exercício de inclusão social e democratização dos meios de comunicação e, em especial, forma de efetivação da ética dos direitos humanos.

O Brasil, tem 120 milhões de usuários de internet, o quarto maior volume do mundo, atrás de Estados Unidos, Índia e China, mostra relatório da Conferência das Nações Unidas sobre Comércio e Desenvolvimento (UNCTAD) ${ }^{1}$. Em 2016, o país foi considerado o segundo que mais usa o WhatsApp, em um levantamento do Mobile Ecosystem Forum (MEF). O primeiro lugar ficou com a África do Sul. Uma grande pesquisa ${ }^{2}$ realizada pelo Comitê Gestor da Internet no Brasil (CGI.br) que operacionaliza, dentre outros a pesquisa denominada TICS KIDS ON LINE no país, indica números alarmantes sobre o contato cada vez mais precoce das crianças e adolescentes com a internet.

Em termos históricos, na pesquisa de Evelin Sofia Konig ${ }^{3}$ há a localização que o avanço no Brasil se deu nos últimos 20 anos, quando os brasileiros aderiram à nova tecnologia e se inscreveram de forma maciça nas redes sociais que se apresentavam. O número de

\footnotetext{
1 Informação disponível em http://unctad.org/en/pages/PressRelease.aspx?OriginalVersionID=432 . Acesso em 22/05/19.

${ }^{2}$ https://cetic.br/media/docs/publicacoes/2/tic kids online 2017 livro eletronico.pdf. Acesso em 08/06/19.

${ }^{3}$ KONIG, Evelin Sofia. Bullying: A responsabilidade civil e o dever de indenização. Dissertação de Mestrado. PUCSP, 2013.
} 
indivíduos com acesso à internet aumentou, no ano de 2018, em 10 milhões, sendo também considerado o terceiro pais do mundo em tempo de permanência na internet. Obviamente o aumento e as facilidades da aquisição de smartphones colaborou para esses indicadores, vez que tais dispositivos vem suplantado o acesso por aparelhos fixos, notebooks e outros mais tradicionais.

No entanto, a saúde psíquica dos usuários e também determinados interesses jurídicos não se encontram suficientemente protegidos contra as novas formas de interferência na vida privada e até mesmo de práticas criminosas transnacionais. A ineficiência dos institutos tradicionais para resolver os conflitos existentes na sociedade moderna é indiscutível; a sociedade se sente fragilizada e atemorizada, aceitando, muitas vezes, o risco, o que determina novas posturas do cidadão diante das ameaças sociais que surgem com o mundo cibernético.

Do ponto de vista psicológico, as relações que se propagam eletronicamente podem, por vezes, trazer um contexto de agressão extremamente virulento e desestruturante para as pessoas, contribuindo para o surgimento ou agravamento de problemas emocionais já existentes nos envolvidos. A dependência criada pelo uso de redes sociais cresce e preocupa cada vez mais psicólogos, psiquiatras e estudiosos da área da saúde mental em geral, já que a dependência em um primeiro momento não é vista como tal, gera prazer ao usuário, que vai cada vez necessitando de crescentes estímulos para conseguir seu equilíbrio. "O efeito seria comparável ao da dependência de substâncias químicas no sistema nervoso central, segundo a Associação Brasileira de Psiquiatria. (ABP). ${ }^{4}$

Apesar da exigência atual ser de aquisição de novas competências, há que valorizarmos a necessidade que existe das relações serem debatidas, ventiladas e reguladas, principalmente quando já se detecta que elas extrapolam em muito a função precípua para a qual foram concebidas.

\section{CONSIDERAÇÕES JURÍDICAS}

O discurso jurídico somente será adequado e racional se produzido, conhecido e aplicado conforme a realidade social vigente. Se a realidade se apresenta como nova, as condições impostas ao Direito são de que este se adapte.

Portanto, deve ser incorporado um conjunto de normas que disponha a respeito dessa nova forma de ofensa a direitos na era digital, de maneira a entender-se um sistema como uma unidade, legitimando a atuação do Direito.

Faz-se necessária a tutela de bens supraindividuais relacionados com o sistema informático. A difusão da tecnologia informática, presença constante na maioria das relações sociais, acarreta o dever de proteção, seja dos bens jurídicos tradicionalmente reconhecidos e lesionados com a utilização da tecnologia informática como modus operandi, seja de novos bens jurídicos, recentemente eleitos como merecedores de tutela penal, surgidos com o advento e a proliferação do sistema informático e da utilização da rede mundial de computadores como serviço de utilidade pública.

No entanto, não podemos perder de vista a necessidade de salvaguarda da dignidade humana inerente a todos os indivíduos, impondo o respeito mútuo entre as pessoas, inclusive no ato da comunicação, e que se opõe a uma interferência indevida na vida privada pelo Estado. A este cabe, ainda, criar condições favoráveis para sua integral realização.

Como observa Flavia Piovesan "a ética dos direitos humanos é a ética que vê no

\footnotetext{
${ }^{4}$ Informação disponível em http://www.abp.org.br/ Acesso em 22/05/19.

${ }^{5}$ PIOVESAN, Flávia. Tráfico de Pessoas para Fins de Exploração Sexual. Disponível em: http://www.justica.sp.gov.br/downloads/biblioteca. Acesso em 22/05/2019.
}

Revista de Direito Brasileira | Florianópolis, SC | v. 24 | n. 9 | p.155-167 | Set./Dez. 2019 
outro um ser merecedor de igual consideração e profundo respeito, dotado do direito de desenvolver as potencialidades humanas, de forma livre, autônoma e plena. É a ética orientada pela afirmação da dignidade e pela prevenção ao sofrimento humano."

Para que a ética democrática esteja realmente a serviço da sociedade, é preciso também que se reconheça o ser humano como cidadão ativo, pleno de direitos e de garantias, que ultrapasse os textos legais para a realidade da vida diária ${ }^{6}$, assegurando-lhe, inclusive, a integração aos meios de comunicação digital e sistema de informática.

É importante sempre lembrarmos que a dignidade humana está ligada a três premissas essenciais: a primeira refere-se ao homem, individualmente considerado, sua pessoalidade e os direitos a ela inerentes, chamados de direitos da personalidade; a segunda, relacionada à inserção do homem na sociedade, atribuindo-lhe a condição de cidadão e seus desdobramentos; a terceira, ligada à questão econômica, reconhecendo a necessidade de promoção dos meios para a subsistência do indivíduo.

\subsection{Dignidade Humana}

Jorge Miranda explica que "Característica essencial da pessoa - como sujeito, e não como objecto, coisa ou instrumento - a dignidade é um princípio que coenvolve todos os princípios relativos aos direitos e também aos deveres das pessoas e à posição do Estado perante elas. Princípio axiológico fundamental e limite transcendente do poder constituinte, dir-se-ia mesmo um metaprincípio ${ }^{7}$."

Ressaltamos que a dignidade decorre da própria natureza humana, o ser humano deve ser sempre tratado de modo diferenciado em face de sua natureza racional. O seu respeito não é uma concessão do Estado, mas nasce da própria soberania popular, ligando-se a própria noção de Estado Democrático de Direito ${ }^{8}$.

Os direitos fundamentais, por sua vez, constituem "o conjunto institucionalizado de direitos e garantias do ser humano que tem por finalidade básica o respeito a sua dignidade, por meio de sua proteção contra o arbítrio do poder estatal e o estabelecimento de condições mínimas de vida e desenvolvimento da personalidade humana"”.

$\mathrm{Na}$ área dos direitos fundamentais, passamos por várias gerações (dimensões), desde as liberdades públicas negativas, os direitos positivos, além daqueles relacionados com a autodeterminação informativa e à informática de modo geral. Lembramos também aqueles pautados na interdisciplinaridade, com foco nas questões éticas e jurídicas, decorrentes do progresso científico médico-biológico e sua repercussão na sociedade e no sistema de valores, tanto atual como futuro; funda-se na sentida necessidade de construção de princípios, regras e valores que tenham a capacidade de compatibilizar os direitos consolidados com as novas perspectivas que se apresentam à realidade humana, bem como a preservação e respeito à própria vida em sua intimidade biológica.

É sabido que a existência de direitos fundamentais separadas de sua garantia de nada vale, pois, conforme Jorge Miranda, "Os direitos permitem a realização das pessoas e têm interferência imediata nas esferas jurídicas, enquanto as garantias estabelecem-se em função com o nexo que possuem com aqueles ${ }^{10}$ ".

O direito é sempre impregnado de conteúdo ideológico e de significação política.

${ }^{6}$ SILVA, Marco Antonio Marques da. Cidadania e Democracia: instrumentos para efetivação da dignidade humana. In: Tratado Luso-Brasileiro da Dignidade Humana, $2^{a}$ edição. São Paulo: Quartier Latin, 2009, p.232.

${ }^{7}$ MIRANDA, Jorge. A Dignidade da Pessoa Humana e a Unidade Valorativa do Sistema de Direitos Fundamentais, in Tratado Luso-Brasileiro da Dignidade Humana, 2a edição. São Paulo: Quartier Latin, 2009, p. 170.

${ }^{8}$ SILVA, Marco Antonio Marques da. in: Tratado Luso-Brasileiro da Dignidade Humana, $2^{\circ}$ edição. São Paulo: Quartier Latin, 2009, p. 227.

${ }^{9}$ MORAES, Alexandre de. Direitos Humanos Fundamentais. São Paulo: Atlas, 2000, p. 39.

${ }^{10}$ MIRANDA, Jorge. Manual de Direito Constitucional. t. IV, $4^{\text {a }}$ Ed. Coimbra Editora, 2008, p. 89.

Revista de Direito Brasileira | Florianópolis, SC | v. 24 | n. 9 | p.155-167 | Set./Dez. 2019 
Com efeito, nossa Constituição Federal aos mencionar direitos e garantias fundamentais o faz usando essas expressões e, muitas vezes, há confusão nos seus sentidos.

Os direitos têm por destaque o caráter declaratório ou enunciativo, enquanto que as garantias são marcadas pelo seu caráter instrumental, isto é, os meios para obtenção ou reparação dos direitos violados, segundo Vidal Serrano Nunes Júnior e Luis Alberto David Araujo ${ }^{11}$.

Ainda nessa linha de raciocínio, no tocante à globalização, pautada em especial na sociedade da informação, o tratamento jurídico não pode ser diferente. A tutela de bens supraindividuais, atrelada à informática, internet, redes sociais entre outros, deve receber maior atenção, com vista a assegurar a todos os meios de proteção aos direitos fundamentais, estabelecendo-se mecanismos eficazes de inserção das pessoas no mundo digital, mas de maneira condizente com os valores inerentes ao respeito e efetivação da Dignidade Humana.

A grande questão que se enfrenta, na atualidade, em termos de violação aos direitos individuais e da personalidade está relacionada ao cyberbullying.

O bullying, que é uma das múltiplas manifestações de agressão e de violência entre pares, incide em meios diversos onde há certa concentração de jovens; destaca-se no cenário atual pela facilidade de propagação com que se apresenta; meios eletrônicos e virtuais passaram a ser os grandes atores desta peça cujo desfecho é comumente trágico.

Cabe dizer que, quando da utilização de ferramentas de telecomunicações, para a prática do bullying, este fenômeno negativo da contemporaneidade ganha forma especializada e é rotulado de cyberbullying. Acumula-se ao fenômeno agregando força e virulência a possibilidade do anonimato do agressor e a crença da impunidade que a prática lhe confere.

O "efeito manada" - termo trazido por Azevedo, Miranda e Souza ${ }^{12}$ - alerta para a seriedade com que esta espécie de violência se apresenta e é destacada pela velocidade, ou melhor, pela rapidez com que as ofensas conseguem ser divulgadas, atingindo o maior número de pessoas, o que faz, inevitavelmente, aumentar o temor da ridicularização da vítima e até mesmo por conquistar adeptos desta prática negativa num sentimento de que é "bacana constranger o próximo". Outro fator que caracteriza e reforça a prática do bullying ou do cyberbullying é a incapacidade física e/ou psicológica para responder aos ataques vexatórios e aniquilantes.

Antes mesmo de adentrarmos ao nível constitucional da discussão, cumpre analisar o ordenamento infraconstitucional. Assim como o bullying, o cyberbullying viola não apenas os princípios orientadores do Código Civil, mas como artigos expressos desta lei.

$\mathrm{O}$ direito da personalidade pode ser conceituado como o conjunto de atributos inerentes à condição humana (e jurídica por equiparação) entendidos como direito a imagem, nome, honra, voz, nome etc. Ainda que os limitados artigos civilistas digam respeito a poucos direitos, certo é que não esgotam o tema e podem ter reflexos em demais direitos, atraindo para a temática da personalidade ideários jurídicos não localizados entre os referidos dispositivos.

Esses direitos são aqueles considerados mínimos para a convivência digna em sociedade, razão pela qual é forte a carga protecionista que os reveste. Com efeito, é que a regra geral se faz pela irrenunciabilidade e inalienabilidade, sendo sua flexibilização medida excepcional.

\subsection{Intimidade, vida privada, honra e imagem}

No tocante a proteção constitucional, dispõe o artigo $5^{\circ}$, inciso $X$, Constituição

\footnotetext{
${ }^{11}$ NUNES Júnior, Vidal Serrano; ARAÚJO, Luiz Alberto David. Curso de Direito Constitucional.

São Paulo: Saraiva, 2001.p.103.

12 AZEVEDO, Jefferson Cabral Azevedo; MIRANDA, Fabiana Aguiar de; SOUZA, Carlos Henrique Medeiros de. Reflexões acerca das estruturas psíquicas e a prática do Ciberbullying no contexto da escola. Intercom-RBCC, v. 35, n.2, p.247-265, jul /dez, 2012.
} 
Federal: "São invioláveis a intimidade, a vida privada, a honra e a imagem das pessoas, assegurando o direito à indenização pelo dano material ou moral decorrente de sua violação".

A vida humana, relativamente à intimidade e vida privada, divide-se em duas esferas autônomas, isto é, pública e privada; esta última, por sua vez, tem a divisão entre a privacidade e a intimidade.

Assim, a vida privada encerraria as situações de opção pessoal que, em muitos casos, podem requerer a comunicação a terceiros. $\mathrm{O}$ chamado direito à privacidade constitui níveis de relacionamento social que o indivíduo habitualmente mantém oculto ao público em geral, resguardando-o da publicidade (vida familiar, amorosa, negócios, lazer e outros).

Tércio Sampaio Ferraz $\mathrm{Jr}^{13}$ aponta a intimidade como sendo "um âmbito mais exclusivo da vida privada" (ex: diário íntimo, segredo sob juramento, as próprias convicções, situações indevassáveis de pudor pessoal, o segredo íntimo cuja mínima publicidade constrange). No direito à intimidade o titular deseja manter impenetrável este direito, mesmo aos mais próximos (ex: orientação sexual).

Para Vidal Serrano, "a intimidade seria um núcleo mais restrito da vida privada, enfim uma privacidade qualificada, na qual se resguarda a vida individual de intromissões da própria vida privada, reconhecendo-se que não só o poder público ou a sociedade podem interferir na vida individual, mas a própria vida em família, por vezes pode vir a violar um espaço que o titular deseja manter impenetrável mesmo aos mais próximos, que compartilham consigo a vida cotidiana ${ }^{14}$ ".

A honra recebe proteção jurídica da Constituição Federal (artigo $5^{\circ}$, inciso X). No âmbito internacional, a Convenção Interamericana de Direitos Humanos - Pacto de São José da Costa Rica, também reconhece a proteção à honra: Artigo 11. Toda pessoa tem direito ao respeito de sua honra e ao reconhecimento de sua dignidade.

A honra ainda pode ser dividida em subjetiva, ou seja, juízo de valor que a pessoa faz de si mesmo, e honra objetiva, referente à reputação com que é conhecida na sociedade.

No tocante à imagem, Walter Moraes pontuava: "é compreendida como sendo toda exteriorização da personalidade humana ${ }^{15}$ ".

E ainda, Maria Helena Diniz aponta:

“[...]o direito à imagem é autônomo, não precisando estar em conjunto com a intimidade, a identidade, a honra etc., embora possam estar, em certos casos, tais bens a ele conexos, mas isso não faz com que sejam partes integrantes um do outro".

“[...] não se pode negar que o direito à privacidade ou à intimidade é um dos fundamentos basilares do direito à imagem, visto que seu titular pode escolher como, onde e quando pretende que sua representação externa (imagem - retrato) ou sua imagem - atributo seja difundida ${ }^{16}$ ".

Segundo Massimo Palazzolo ${ }^{17}$, os direitos à imagem são autônomos e devem ser tratados de maneiras distintas, possuindo, três variações protegidas constitucionalmente: imagem - retrato: inserida genericamente, não tem uma extensão restritiva ( $\operatorname{art} .5^{\circ}, \mathrm{X}, \mathrm{CF}$ ); imagem - atributo: a CF protege não só o retrato da pessoa e o conjunto dessa imagem, mas

\footnotetext{
${ }^{13}$ FERRAZ Jr., Tércio Sampaio. Sigilo de dados: direito à privacidade e os limites à função fiscalizadora do estado. Revista da Faculdade de Direito da USP, São Paulo, v.88, 1993, p.439.

${ }^{14}$ SERRANO, Vidal. A Proteção Constitucional da Informação e o direito à crítica jornalística. São Paulo: FTD, 1997, p.91.

${ }^{15}$ MORAES, Walter. Direito à própria imagem. Revista dos Tribunais, no 443, set/1972, p. 80-81.

${ }^{16}$ DINIZ, Maria Helena. Código Civil anotado. $8^{\text {a }}$ ed. . São Paulo: Saraiva, 2002, p.33

${ }^{17}$ PALAZZOLO, Massimo. Persecução Penal e Dignidade da Pessoa Humana. São Paulo: Quartier Latin, 2007, p. 83.
}

Revista de Direito Brasileira | Florianópolis, SC | v. 24 | n. 9 | p.155-167 | Set./Dez. 2019 
também uma "imagem", diferente do retrato (art 5\%, V) e imagem - autoral: proteção ao direito de arena, como forma de participação nas atividades desportivas e artísticas (art. $5^{\circ}$. XXVIII).

\section{CONSIDERAÇÕES PSICOLÓGICAS}

A inclusão da tecnologia digital na vida cotidiana dos humanos é crescente e trouxe uma grande revolução para a comunicação entre os seres vivos. A quantidade de informação que circula hoje na chamada "janela para o mundo" e nas redes sociais permite que muitos autores denominem a fase atual como a "era da informação", o que não necessariamente vem em conjunto com a "era da compreensão".

O mundo digital revolucionou velhos padrões de relacionamento e de contato humano, já que o tempo e o espaço passam a ter a dimensão da imediatez, da alta velocidade e para muitos da obscuridade, já que podemos falar sem sermos vistos, comunicarmos ideias além de também podermos nos manter no anonimato, sem qualquer correção ou punição.

A virtualidade do real (Castells, 2000) pode gerar mudanças em uma gama de sentimentos, os quais ecoam em cada pessoa, instituição e grupo de formas diferentes. No caso das novas tecnologias, o modo como cada um irá se relacionar com o desconhecido, o surpreendente, o inovador, o provocativo e instigador está diretamente relacionado às características de personalidade e condições emocionais de cada um; além disso, também o próprio histórico sociocultural molda os efeitos dessa relação.

Os meios tecnológicos fazem parte do dia-a-dia de crianças, jovens e adultos, e, assim como cada descoberta pode descortinar outras, elas também podem ter utilizações diversas, completamente distanciadas dos objetivos iniciais de sua concepção. Assim, o que foi feito para agilizar a comunicação, otimizar, levar conhecimento, globalizar descobertas, pode também servir para agredir, ridicularizar, ameaçar e até causar danos psicológicos significativos entre as pessoas.

Se é fato que em uma mesma descoberta ou facilidade da vida moderna existem caminhos antagônicos para se usufruir dos mesmos conceitos ou benevolências dos achados, é também verdade que nas relações travadas em períodos iniciais de nossa história surgem dificuldades e intrigas que muitas vezes nem consideramos serem possíveis de ocorrer. Em outras palavras, a preocupação ética nem sempre está a postos nos diversos achados científicos da humanidade.

Ao pensarmos que duas ou mais crianças em idades escolares, em uma fase em que o período de aquisição do conhecimento, das descobertas, da curiosidade estaria mais aguçado, teriam naturalmente uma atração facilitadora, seria de se estranhar que eclodissem sentimentos conhecidos como menos nobres, tais como a inveja, a agressividade, o racismo, e uma infinidade de outros que não caberia aqui enumerarmos.

No entanto isso não corresponde à realidade. As relações ainda que iniciadas na fase denominada da "inocência" já podem trazer agressividade e grande poder de destruição para o outro; relações que deveriam ser despretensiosas podem, na atualidade, facilmente descortinarem um universo de dor, preconceito, intimidação e tudo aquilo que pode fazer uma relação de amizade e cooperativismo, virar algo em que haja um algoz e uma vítima.

As formas de agressão entre as pessoas, diretas ou indiretas trazem sempre algum tipo de prejuízo às vítimas, tanto do ponto de vista da saúde física, como da emocional. Uma das formas de manifestação do comportamento agressivo é denominada de bullying, conceito já descrito no início do século XX, conforme Guilherme Wendt e Carolina Lisboa (2013) ${ }^{18}$. Segundo os autores, o conceito foi explicitado na década de 70 pelo psicólogo norueguês Dan Olweus, quando na universidade de Bergen ele iniciou suas observações sobre agressores e suas vítimas, ainda que à

${ }^{18}$ WENDT, Guilherme Welter; LISBOA, Carolina Saraiva de Macedo. Agressão entre pares no espaço virtual: definições, impactos e desafios do cyberbullying. Psic. Clin.,vol. 25, n.1, p. 73-87, Rio de Janeiro, 2013

Revista de Direito Brasileira | Florianópolis, SC | v. 24 | n. 9 | p.155-167 | Set./Dez. 2019 
época não havia qualquer interesse das escolas norueguesas sobre o assunto.

Foi necessário que 3 estudantes noruegueses, na faixa etária entre 10 e 14 anos, cometessem suicídio, sob forte influência dessa prática denominada bullying, para que o país voltasse o interesse para suas pesquisas. Antes disso, em 1904, há notícias que o primeiro presidente da American Psychological Association, assinalou a existência do fenômeno.

No Brasil, a Associação Brasileira Multiprofissional de Proteção à Infância e a Adolescência (ABRAPIA), entidade que estuda o assunto, afirma que no Brasil o tema "bullying" veio à tona há pouco tempo, havendo estudos mais direcionados apenas a partir dos anos 90.

Hoje, o bullying, é considerado uma das formas de assédio existente em qualquer sociedade. Conforme Evani Z. Marques da Silva e Lídia R.F. Castro, trabalho que mostra as áreas de intersecção entre Psicologia e Direito, a descrição do bullying encontra-se como sendo "palavra inglesa que se refere a um desejo consciente e deliberado de maltratar alguém e colocá-la sob tensão; o termo refere-se a comportamentos agressivos e antissociais e tem como base o verbo "to bully', que quer dizer tratar abusivamente, intimidar ${ }^{19}$."

É de se destacar também os estudos de Cleodenice Aparecida Zonato Fante , especialista no estudo do bullying e que caracteriza-o como sendo "um comportamento cruel e intrínseco nas relações interpessoais, em que os mais fortes convertem os mais frágeis em objetos de diversão e prazer, através de "brincadeiras" que disfarçam o propósito de maltratar e intimidar 20."

Há que se salientar que o fenômeno bullying não é representado por uma mera briga entre duas pessoas ou grupos; para que haja o diagnóstico de bullying deve haver sempre um desequilíbrio de forças, uma coação, quando a vítima é compelida a fazer algo que não quer, pois alguém a constrange - física ou moralmente - para tal. Esse assédio pode ser veiculado de forma direta ou indireta. No bullying direto, há ataques relativamente abertos contra a vítima, e no bullying indireto, os ataques são perpetuados de forma a isolar alguém, e/ou excluir intencionalmente alguém de um grupo, mas sempre por meios pouco explícitos e pouco declarados.

É justamente essa segunda forma citada de bullying, o indireto, que gostaríamos de chamar a atenção, devido à sutileza de como se veicula e a virulência alarmante no tocante ao poder de abrangência e destrutividade emocional das pessoas.

Os bullies, aqueles que praticam o bullying tem migrado rapidamente para os espaços virtuais, devido a facilidade do anonimato que esses ambientes oferecem e também pelo aumento significativo dos relacionamentos que ocorrem pela via virtual - total ou parcialmente.

Segundo João Amado e Armanda Matos ${ }^{21}$ estudiosos portugueses da área da educação, apesar da maior conscientização sobre o bullying, verifica-se que o fenômeno dissemina-se mais facilmente pela via digital. As relações travadas ou continuadas pelos meios eletrônicos são, em alguns casos, alvo do bullying virtual ou cyberbullying, o qual acarreta consequências iguais ou piores do que as causadas fora do espaço virtual, em função da velocidade e da blindagem que o agressor consegue escondendo-se muitas vezes atrás de apelidos, mudanças rápidas de endereços, criando blogs e perfis falsos, alterando fotografias, divulgando montagens fotográficas em sites diversos, fazendo-se passar pela própria vítima para divulgar conteúdos sexistas, bizarros, raciais, preconceituosos e difamatórios de modo geral.

Em uma pesquisa da ONG Safernet ${ }^{22}$, realizada com quase 3.000 pessoas de 9 a 23 anos, mostra que $20 \%$ já receberam textos ou imagens eróticas de amigos e conhecidos e que $6 \%$ repassaram esse tipo de conteúdo, sendo que a maioria o fez mais de cinco vezes. Com isso, o

\footnotetext{
${ }^{19}$ SILVA, Evani Zambon Marques da; CASTRO, Lídia Rosalina Folgueira de. Psicologia Judiciária. São Paulo: Edipro, 2011, p. 52.

${ }^{20}$ FANTE, Cleodenice Aparecida Zonato. Fenômeno bullying. São Paulo: Versus, 2005, p.45.

${ }^{21}$ Amado, João; Matos, Armanda. O Cyberbullying entre os Comportamentos de Risco Online. In: Miranda, Guilhermina Lobato (org.). Psicologia dos Comportamentos Online. Lisboa: Relógio D’Água Editores. 2015. p.81105.

${ }^{22}$ Folha de São Paulo. Caderno Cotidiano p. C1 de 01/12/13.
}

Revista de Direito Brasileira | Florianópolis, SC | v. 24 | n. 9 | p.155-167 | Set./Dez. 2019 
vazamento desse material tem uma propagação rapidíssima e quase impossível de ser barrada.

No Brasil usualmente é noticiado pela mídia ${ }^{23}$, a morte de jovens. Muitas investigações apontam que são pessoas habitualmente conectadas à internet e tiveram suas intimidades devassadas com a divulgação de fotos e vídeos íntimos. Só para termos uma ideia, a questão é alarmante a ponto haver desde 2006 na China, um centro para tratar da dependência da internet, vez que o problema é considerado de saúde pública no país. No Brasil temos laboratórios e instituições ${ }^{24}$ que se propõe a tratar de tal dependência digital, tais como compulsões pelos smartphones, jogos eletrônicos e outros problemas físicos e mentais derivados.

$\mathrm{Na}$ área da neurociência defende-se que tempo demais diante das telas pode conectar o cérebro das crianças a ponto de dificultar o aprendizado em sala de aula e na vida de forma geral $^{25}$. Assim, as agressões e comportamentos aprendidos pelas redes sociais, geram uma dificuldade de articulação de raciocínio para os jovens, impossibilitando com que as vítimas saiam ilesas das situações as quais são conduzidas. Segundo Ana Beatriz Barbosa Silva ${ }^{26}$ as consequências psicológicas são incalculáveis e, muitas vezes, chegam a atingir os familiares e amigos próximos.

As pessoas vitimadas pelas agressões on line ou pelo cyberbullying são semelhantes aquelas expostas ao bullying propriamente dito. Nos diversos estudos levantados ${ }^{27,28}$ há unanimidade sobre os efeitos devastadores na saúde física e emocional das vítimas. Dentre eles, destacamos sintomas de insegurança, ansiedade, crises de choro, dificuldade de concentração, pesadelos, ideias suicidas, perda da autoconfiança, redução da auto-estima, dificuldade de ajustamento, de relacionamento íntimo.

No ano de 2015, o Conselho Nacional de Justiça organizou uma cartilha sobre bullying ${ }^{29}$, com o fito de levar orientação e justiça para as escolas; o material explicita também as graves consequências para as vítimas e reforça as marcas profundas provenientes das agressões que serão levadas até a vida adulta e necessitarão de apoio psiquiátrico e/ou psicológico para a superação do problema. Segundo o documento, os problemas mais comuns são: desinteresse pela escola; problemas psicossomáticos; problemas comportamentais e psíquicos como transtorno do pânico, depressão, anorexia e bulimia, fobia escolar, fobia social, ansiedade generalizada, entre outros. $\mathrm{O}$ bullying também pode agravar problemas preexistentes, devido ao tempo prolongado de estresse a que a vítima é submetida. Em casos mais graves, podem-se observar quadros de esquizofrenia, homicídio e suicídio.

A Lei 13185/15 institui o combate a intimidação sistemática, derivando e fomentando a criação não só de cartilhas como de diversos programas de conscientização por todo o país. Mais recentemente, a Lei 13.819/2019, que institui a Política Nacional de Prevenção da Automutilação e do Suicídio, prevê que notificação compulsória de caráter sigiloso, para os casos de tentativa de suicídio e automutilação por estabelecimentos de saúde, segurança, escolas e conselhos tutelares.

As pessoas que praticam o cyberbullying precisam de ajuda assim como as vítimas. Embora o uso excessivo da internet não tenha sido ainda catalogado como adição pelo DSM-V (Disease Statistical Mental Disorders) que é um documento de referência mundial para a avaliação

\footnotetext{
${ }^{23}$ Folha de São Paulo. Caderno Cotidiano p. C3 de 01/12/13.

${ }^{24}$ Ambulatório Integrado do Controle dos Impulsos / PRO-AMITI; Instituto Delete dentre outras.

25 YOUNG, Kimberly; ABREU. Cristiano N. Trad.: Mônica G. Armando. Dependência de internet em crianças e adolescentes. Porto Alegre: Artmed, 2019. e-Pub.

${ }^{26}$ SILVA, Ana Beatriz Barbosa. Bullying - mentes perigosas nas escolas . Rio de Janeiro: Fontanar, 2010, p.128.

27 WENDT, Guilherme Welter; LISBOA, Carolina Saraiva de Macedo. Agressão entre pares no espaço virtual: definições, impactos e desafios do cyberbullying. Psic. Clin. , vol. 25, n.1, p. 73-87, Rio de Janeiro, 2013.

${ }^{28}$ AZEVEDO, Jefferson Cabral Azevedo; MIRANDA, Fabiana Aguiar de; SOUZA, Carlos Henrique Medeiros de. Reflexões acerca das estruturas psíquicas e a prática do Ciberbullying no contexto da escola. Intercom-RBCC, v. 35, n.2, p.247-265, jul /dez, 2012.

${ }^{29} \mathrm{http}$ ://www.cnj.jus.br/files/conteudo/destaques/arquivo/2015/04/0d95535ddf206bc192c4e05356e35c83.pdf Aceso em 22/09/18.
}

Revista de Direito Brasileira | Florianópolis, SC | v. 24 | n. 9 | p.155-167 | Set./Dez. 2019 
da saúde mental, tal como ocorre com o uso abusivo de jogos de azar, pesquisadores europeus ${ }^{30}$ tem preferido usar o termo "utilização excessiva da internet" e não "adição" que traz uma conotação de doença, dependência ou uso patológico.

O perfil dos cyberbullies possui aspectos nebulosos pela dificuldade inerente de identificação que a situação apresenta. São geralmente adolescentes ou pessoas imaturas e em muitos casos portadoras de transtornos mentais de tipos variados. Estudos referem que em alguns casos foram vítimas do próprio mal que propagam e acabam também, segundo Ana Beatriz Barbosa Silva ${ }^{31}$ por existirem como um reflexo perfeito da cultura embasada na insensibilidade e na total ausência de responsabilidade coletiva.

Há que se ter claro, que hoje, segundo os pesquisadores Jefferson Azevedo, Fabiana Miranda e Carlos Henrique Souza ${ }^{32}$ "a escola e a família não são os únicos referenciais para a formação das identidades e estruturação psíquica, o não lugar proporcionado pelas novas tecnologias adentrou tais ambientes restritos e concorre para estabelecer novos valores e parâmetros de convivência, de relações e propagação de poder e formação de identidades, sejam patológicas ou não."

Problemas diversos nas relações familiares e nas próprias instituições de ensino podem incitar a ocorrência desse tipo de violência explanada, pela própria defasagem ou lentidão na alteração de papéis e atitudes para o acompanhamento dos jovens. A vertente, como já dito acima, para explicarmos o surgimento e o alastramento do problema nunca será única e simplesmente dar a ela o tratamento usualmente feito por algumas correntes da psicologia para a questão do alastramento da violência seria extremamente reducionista. Antigamente era quase que linear pensarmos que o abusado de ontem - no meio familiar- seria o abusador de amanhã; hoje, nem sempre o cyberbullie de hoje será o assediador moral e/ou sexual de amanhã. Mas, há que se oferecer, como diz um estudo europeu denominado Projeto EU Kids Online, que contabilizou mais de 400 estudos sobre crianças e internet, que há necessidade de oferecermos aos jovens uma janela mais bonita de seu quarto do que a internet oferece.

Aceitar que a convivência com o mundo digital não é neutra e segura é o primeiro passo que as famílias devem dar. Sair do comodismo de ter um filho em casa, ainda que on line, dispor de tempo para a relação familiar e assumir verdadeiramente que os perigos da rua também estão presentes na internet, é tarefa árdua, que tanto pais, educadores e a sociedade em geral, precisam assumir. Nunca é tarde para se diagnosticar uma dependência, um transtorno psíquico, um quadro psicopatológico, que tem levado tantos jovens a, no ápice da dor, atentarem contra a própria vida.

\section{CONCLUSÃO}

Assim como a era digital é uma realidade crescente, também deve haver um incentivo à conscientização da relevante educação digital, suas vicissitudes e possibilidades.

Os benefícios e facilidades trazidos pelos sistemas de informática e do mundo cibernético são irreversíveis; paradigmas foram alterados e o modelo de vida privada rendeuse às múltiplas interações, às redes sociais; grandes distâncias não mais existem, principalmente quando se fala em propagação de dados e informações.

Associado a todos esses benefícios, no entanto, surgiram novas questões que

\footnotetext{
${ }^{30}$ MORAIS, Tito. Viciados no Quarto. In: PONTE, Cristina et al (orgs.). Crianças e Internet em Portugal. Coimbra: Minerva, 2012.

${ }^{31}$ SILVA, Ana Beatriz Barbosa. Bullying - mentes perigosas nas escolas. Rio de Janeiro: Fontanar, 2010, p.133.

${ }^{32}$ AZEVEDO, Jefferson Cabral Azevedo; MIRANDA, Fabiana Aguiar de; SOUZA, Carlos Henrique Medeiros de. Reflexões acerca das estruturas psíquicas e a prática do Ciberbullying no contexto da escola. Intercom-RBCC, v. 35,n. 2,p. 247-265, jul /dez, 2012.
} 
desafiam a organização social, constatando-se a fragilidade do atual sistema jurídico para securitização da vida privada e tutela dos interesses supraindividuais.

Com o intuito de coibir práticas danosas como o cyberbullying e visando à proteção dos direitos fundamentais, em tema de sistema informático, imperiosa a adoção de medidas de conscientização e divulgação dessas práticas e suas consequências, tendo em vista que a ignorância das vítimas é arma dada aos aliciadores e aos infratores.

A repressão embora seja necessária, não tem sido suficiente. Torna-se imperioso investir na prevenção, o que só poderá ser feito através da conjugação de vontades políticas e esforços do governo, dos setores privados e de toda sociedade.

Além disso, imprescindível a participação da família e da escola. No entanto, o preponderante deve ser a relação, isto é, de abertura e acolhimento, antes de qualquer atitude de reprovação e censura. Muitas vezes confunde-se a capacidade técnica dos filhos com maturidade e capacidade crítica de analisar e resolver problemas. Com isso, desnuda-se uma realidade em que o jovem vai se abrindo cada vez mais porque entende - erroneamente - que aquele território é seguro e confiável.

Sem qualquer visão de censura, o território da internet deve ser balizado com marcadores claros, que traduzam limites e possibilidades de uso sem abuso; uma meta a ser conquistada para o futuro.

É inquestionável que o cyberbullying é uma violência psicológica que acarreta complicações emocionais significativas tanto para a vítima como para aquele que a perpetua, na medida em que este último, além de toda perversidade emanada, pode desenvolver certa dependência e prazer nessa prática.

Portanto, deve ser estabelecido um plano ético, multidisciplinar, para promoção do ser humano para a justiça e para a paz, sem o que a dignidade não se realiza, tornando inócuos os fins sociais.

São inúmeros mecanismos e dispositivos para a proteção dos direitos ofendidos pelo cyberbullying, mas resta saber por que o confronto é tão difícil?

Em artigo intitulado "A defesa da dignidade humana em primeiro lugar" "33, veiculado pela rádio do Vaticano, vivemos suma sociedade em que não faltam poderes e forças para produzirem a "cultura do descartável" que tende a se tornar mentalidade comum. E, em complementação, o Observatório Romano, jornal que veicula notícias oficiais do Vaticano desde 1861, apesar de valorizar as extraordinárias possibilidades oferecidas pelo uso da internet, admite que o confronto é necessário e atualiza as discussões em torno da fé e da cultura. "Hoje mudam os tempos, mas o terreno do confronto é o mesmo. E por isso é necessário estarmos cientes de que certamente encontraremos moedas falsas, ilusões perigosas e armadilhas" que devemos evitar ${ }^{34}$."

Considerando os históricos das vítimas de cyberbullying, é frequente a coincidência de serem pessoas mais tímidas ou que, durante as primeiras agressões morais, não impingiram uma postura a fim de obstar a continuidade das violações, apenas se quedaram inerte sem qualquer reação aparente. Por outro lado, a demonstração de fraqueza, vulnerabilidade e até mesmo o excesso de confiança no outro faz do agressor uma ser equivocadamente superior e mais forte, robustecendo sua capacidade persuasiva perante os demais.

Quando da ocorrência de bullying, salvo em casos pontuais, a maioria das pessoas não adota postura coercitiva em defesa do ofendido; muito pelo contrário, acabam por divulgar e propagar o bullying como forma de entretenimento da pior espécie.

Embora não possamos falar em 'culpa', pois não é apenas a vítima que muitas vezes concorre para essa importunação ofensiva, mas igualmente das pessoas ao seu redor. Respeitando opiniões divergentes, não faltam apenas meios jurídicos de coerção dos agressores, e sim uma

\footnotetext{
${ }^{33}$ Disponível em www.news.va.pt/news. Acesso em 08/09/18.

${ }^{34}$ Disponível em www.osservatoreromanno.va/portal . Acesso em 08/09/18.
} 
conscientização da população e da sociedade, individual e coletiva, no sentido da fraternidade, do respeito ao próximo, da harmonização social e coletiva em prol do respeito à dignidade da pessoa humana, raiz da liberdade e da justiça.

Como qualquer vício, a dependência digital que está na raiz da prática do cyberbullying, pode e deve ser controlada. É preciso coragem, clareza e vontade de se inserir em outro tipo de rede, a da valorização da vida presencial.

\section{REFERÊNCIAS}

AMADO, João; MATOS, Armanda. O Cyberbullying entre os Comportamentos de Risco Online. In: Miranda, Guilhermina Lobato (org.). Psicologia dos Comportamentos Online. Lisboa: Relógio D’Água Editores. 2015. p.81-105.

AZEVEDO, Jefferson Cabral Azevedo; MIRANDA, Fabiana Aguiar de; SOUZA, Carlos Henrique Medeiros de. Reflexões acerca das estruturas psíquicas e a prática do Ciberbullying no contexto da escola. Intercom-RBCC, v. 35, n.2, p.247-265, jul /dez, 2012.

CAMPOS, Diogo Leite de. Lições de Direito da Personalidade. Coimbra: Almedina, 1995.

CASTELLS, Manuel. A Sociedade em Rede. Trad. Fernando Henrique Cardoso. São Paulo: Paz e Terra, 2009.

CONSELHO NACIONAL DE JUSTIÇA. Disponível em: http://www.cnj.jus.br/images/programas/justica-escolas/cartilha_bullying.pdf. Acesso em $01 / 12 / 13$.

DINIZ, Maria Helena. Código Civil anotado. 8ª ed., São Paulo: Saraiva, 2002.

FANTE, Cleodenice Aparecida Zonato. Fenômeno bullying. São Paulo: Versus, 2005.

FOLHA DE SÃO PAULO. Caderno Cotidiano de 01/12/13.

FOLHA DE SÃO PAULO. Caderno Ilustríssima de 19/05/19.

FERRAZ Jr., Tércio Sampaio. Sigilo de dados: direito à privacidade e os limites à função fiscalizadora do estado. Revista da Faculdade de Direito da USP, São Paulo, v.88, 1993, p.441-2.

FOUCAULT, Michel Microfísica do Poder. Rio de Janeiro: Graal, 1999.

KONIG, Evelin Sofia. Bullying: A responsabilidade civil e o dever de indenização. Dissertação de Mestrado. PUCSP, 2013.

PIOVESAN, Flávia. Tráfico de Pessoas para Fins de Exploração Sexual. Disponível em: http://www.justica.sp.gov.br/downloads/biblioteca. Acesso em 09.09.2009.

MIRANDA, Jorge. A Dignidade da Pessoa Humana e a Unidade Valorativa do Sistema de Direitos Fundamentais, In: Miranda, Jorge e Silva, Marco Antonio Marques da (coord.) Tratado Luso-Brasileiro da Dignidade Humana, 2a edição. São Paulo: Quartier Latin, 2009. 
MIRANDA, Jorge. Manual de Direito Constitucional. t. IV, $4^{\mathrm{a}}$ ed. Coimbra Editora, 2008.

MORAES, Alexandre de. Direitos Humanos Fundamentais. São Paulo: Atlas, 2000.

MORAES, Walter. Direito à própria imagem. São Paulo: Revista dos Tribunais, nº 443, set/1972, p. 80-81.

MORAIS, Tito. Viciados no Quarto. In: PONTE, Cristina et al (orgs.). Crianças e Internet em Portugal. Coimbra: Minerva, 2012.

NUNES Júnior, Vidal Serrano; ARAÚJO, Luiz Alberto David. Curso de Direito Constitucional. São Paulo: Saraiva, 2001.

OSSERVATORE ROMANO. Disponível em: www.osservatoreromanno.va Acesso em 08/12/13.

PALAZZOLO, Massimo. Persecução Penal e Dignidade da Pessoa Humana. São Paulo: Quartier Latin, 2007.

SERRANO, Vidal. A Proteção Constitucional da Informação e o direito à crítica jornalística. São Paulo: FTD, 1997.

SILVA, Ana Beatriz Barbosa. Bullying - mentes perigosas nas escolas. Rio de Janeiro: Fontanar, 2010.

SILVA, Evani Zambon Marques da; CASTRO, Lídia Rosalina Folgueira de. Psicologia Judiciária. São Paulo: Edipro, 2011.

SILVA, Marco Antonio Marques da. Cidadania e Democracia: instrumentos para efetivação da dignidade humana. In Miranda, Jorge e Silva, Marco Antonio Marques da (coord.) Tratado LusoBrasileiro da Dignidade Humana, $2^{\circ}$ edição. São Paulo: Quartier Latin, 2009.

YOUNG, Kimberly; ABREU. Cristiano N. Trad. Mônica G. Armando. Dependência de internet em crianças e adolescentes. Porto Alegre: Artmed, 2019.e-PUB

WENDT, Guilherme Welter; LISBOA, Carolina Saraiva de Macedo. Agressão entre pares no espaço virtual: definições, impactos e desafios do cyberbullying. Psic. Clin.,vol. 25, n.1, p. 73-87, Rio de Janeiro, 2013. 